\title{
FROM AN IDEA TO A RECYCLING INDUSTRY
}

Leif Jilkén

Institute of Technology, University of Kalmar or Polyplank AB

Sweden

\begin{abstract}
Plastic waste from industrial companies and commerce constitutes a considerable potential for recovery and conservation of resources. But there are hundreds of different sorts of plastic, in other words, plastic waste is a problem due to its heterogenous nature. The possibility of manufacturing commmercially saleable products from unwashed recycled plastics has been very restricted. For its normal range of products, the plastics industry has required absolutely pure raw materials and it has not been economically justifiable to wash and to produce this from recycled material.
\end{abstract}

By adding organic fibres, such as short woodfibres, with the mixed recycled termoplastics, a composite material POLYWOOD is produced. The granulate mixture is extruded to different profiles, called POLYPLANK, that can be handle like wood but which withstands rot, moisture, soil, etc.and is completely recyclable several times.

Polyplank are used for manufacturing of noise barrier sections, recycling yard enclosures, interior fittings in animal boxes etc

\section{Introduction}

The plastics waste deriving from trade and industry constitutes a substantial recovery and resource saving potential. Since the 1950 s the utilazation of plastic products has increased dramatically and large volumes of plastics waste are today in circulation. In Central Europe there is annual aggregate of approx. 8 million tonnes of plastics waste and only one fifth of this volume is at present estimated to become reutilized in the form of material. There exist today several hundred different types of plastics. Usually they are divided into two maincategories: thermosets and thermoplastics. 
Thus, plastics waste is in certain cases a problem due to its heterogeneous character. In order to recover the plastics, ample knowledge is required about quality, composition, volumes and occurerence in different fields of activity.

Up until now, the possibility of manufacturing commercially viable products of recovered plastics has been strictly limited. The plastic industry has for its regular product assortment needed fully pure raw materials and only exceptionally has it been financially justified to manufacture new products out of recovered polluted materials. A research project was initited wich resulted in a new composite material made of unwashed plastics waste and short organics fibres (woodfiber). The composite material, POLYWOOD combines the properties of plastics such as rotresistance etc.with the mechanical charactristics of wood such as nailability and ability to permit being sawed or subject to screwing.

Two patent methodes used in the process technology required for generating POLYWOOD / POLYPLANK. These two patents supplement each other in an exellent way. Products made of this composite definitely have a market within all market sectors where a corrosion-inert material is sought for and which material is as a whole recoverable.

\section{Polymers}

Biological polymers have been around in a natural form since life began and play an extremely important role in plants and animals life, and include starch, proteins, lignin, cellulose, collagen, silk and natural rubber.

Use of synthetic polymers, has increased enormously over the past few decades, because of their relative cheapness, easy to fabricate, low density, chemical inertness and high electrical resistivity. Synthetic polymers derive mainly from oilbased products and include polyethylene PE, polyprop-hylene PP, polyamide PA (nylon), phenolics, synthetic rubber....

Polymers are now accepted as a material group like metals and ceramics. We can separate polymers in two different boxes, see figure 1, depending on type of architecture on polymer molecules. 


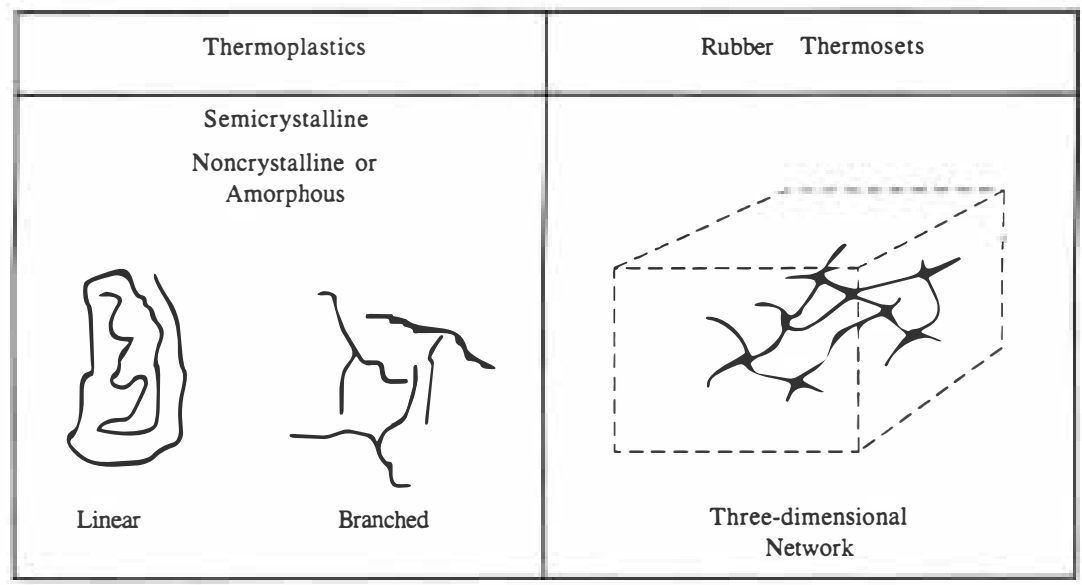

Fig. 1: Three different types of polymers molecules.

Polymer products are made up of long molecules. A typical sample of polyethylene may have molecules which contain an average 50000 atoms and would be $25000 \AA$ long ( $\AA=1 / 10$ meter.). The presence of these macromolecules has an dominant effect upon the properties of polymeric material.

Thermoplastics, which are often referred to just as "plastics" are linear or branched polymers, see figure 1, which can be melted upon the application of heat . They can be moulded and remoulded using conventional techniques and now make up the largest bulk of polymer used. Thermoplastics can be sub-divided into those which partly crystallize on cooling (semicrystalline) and those which do not and are normally used as polymer glasses, non crystalline (amorphous). Over $80 \%$ of plastics are thermoplastic, the main ones being polyethylene PE, polypropylene PP, polyvinylchloride PVC and polystyrene PS; all the other thermoplastics only account for about $7 \%$ of the thermoplastics market.

Thermosets and rubber are heavily cross-linked polymers which are nor-mally rigid and intractable. The consist of dense three-dimensional molecular network, degrade rather than melt on the application of heat.

\section{Organic fibres - woodfibres}

Wood is a natural material built up for fullfil some functions within the growing or living tree. Its tubular structure is a result of that liquid and feeding stuff are able to transport in different directions. The fibres or tubular thicknes differ depend on when it has growned, autumn / winter thick walls (high mecanical stresses) or spring./ summer thin walls (mainfunction is to transport liquids ), this gives a large variation in density in different parts of the tree. Since a huge amount of liquid transport will go on continuously from the roots to the top of a tree 
(500 liters / day) are the helical fiber mainly parallell to the direction of the tree, this gives a high anisotropi in a piece of wood. See figure 2.

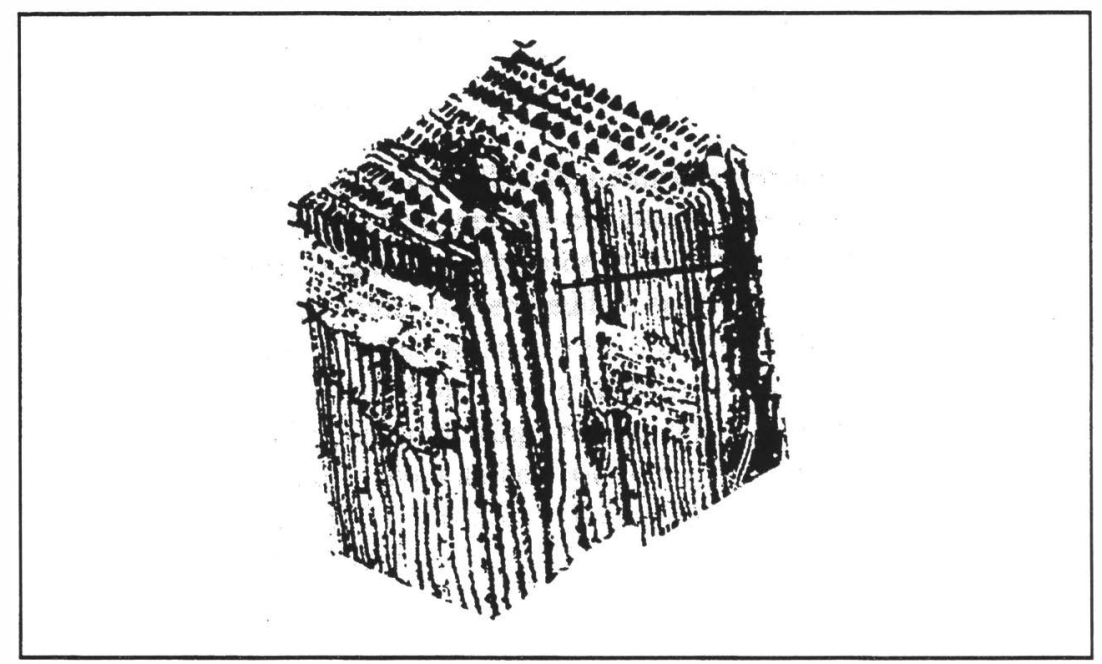

Fig. 2: A piece of wood showing the fiberconstruction.

An interesting observation is that the compactdensity (the density reaching if graining the woodfibres) is relative independent of different type of trees. See figure 3 .

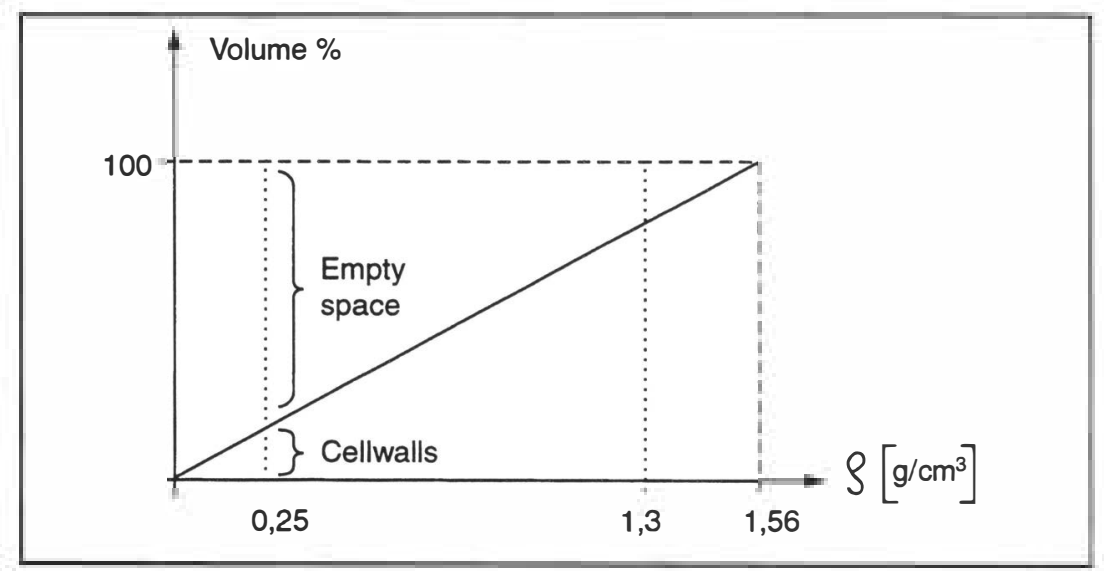

Fig. 3: " Empty space " depending on density. 
The cellwalls are built up of cellulose, hemicellulose and lignin. From a mechanical point of view the construction is, in the walls, such that the mechanical loads transforms to stresses in the chains of cellulosemolecules wich are embedded in lignin. The cellulosemolecules make helicals configuration there the angle of climb can varies. The cellwalls include a lot of voids of different cape and sitz, from a few Ångström up to hundreds Ångström in sitz. This explaines why wood has so enormus "inner suface" of about 400 squaremeter in one gram of dry wood, this gives possibilities to enclose other material as water, oil and polymers.

\section{How to mix together reusable thermoplastics with short fibres from different type of wood.}

The free volyme is the space in a solide or liquid sampel which is not occupied by polymers molecules i.e. the "empty-space" between molecules. In the liquid state it is supposed that the free volume is high so molecular motion is able to take place relatively easily because the unoccupied volume allows the molecules space to move and so change their conformation freely. As the temperature of the melt is lowered the free volume will be reduced, see figure 4. Under the glass - transition temperature region , Tg is polymers so called "frozen ".

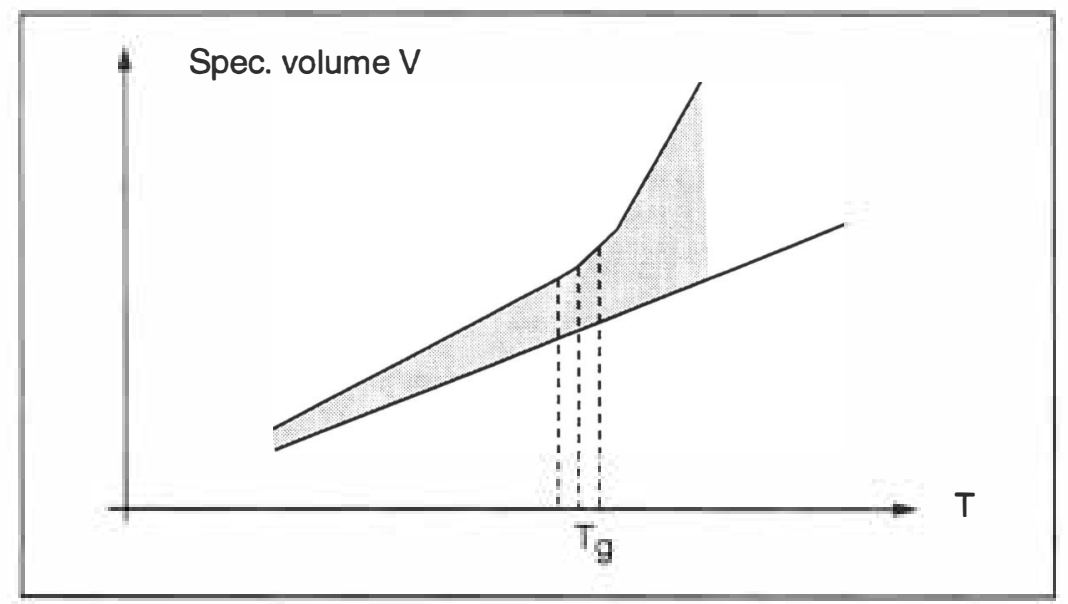

Fig. 4: Schematic illustration of the variation of the specific volume V, of a polymer with temperatu, $T$.. The free volyme is represented by the shaded area.

Mixing the composite should be done above the transition temperature $\mathrm{T} g$ becuase the molecules move relativly free there. The fibres we choose should be recovererable and damage the production equipment as little as possible, therefore we select short organic woodfibers. This fibre has an "inner surface" wich gives a good coupling effect. 
The choise of form factor of the fibre, that is the ratio of fibre length to fibre diameter, gives different mechanical stiffnes for the composite material. The formfactor shall be over twenty to give an reinforcement effect. Call attention to that the form factor of the mixed fibre materials must exhibits dispersion, see figure 5 . in such a way that the values of their moduli of elasticity $\left(E_{i j}\right)$, the moduli in shear $\left(\mathrm{G}_{\mathrm{ij}}\right)$, and Poisson's ratios $\left(\mathrm{v}_{\mathrm{ij}}\right)$, assume a discontinnous distribution.

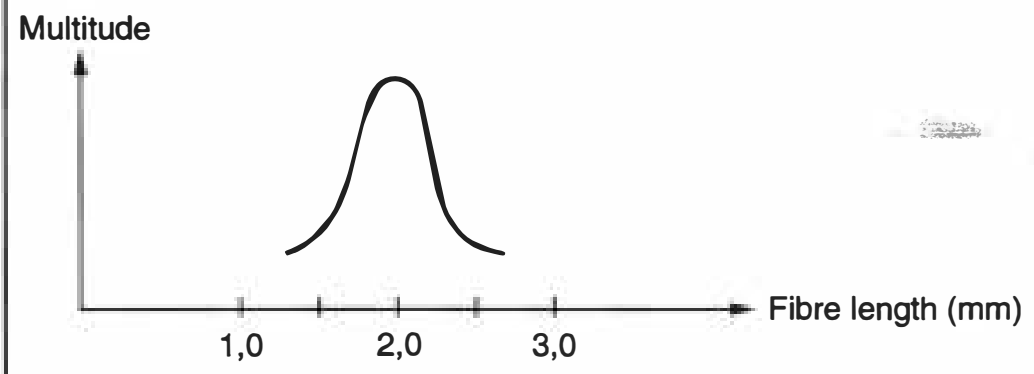

Fig. 5: An example of fibre- dispersion.

The fibre is exceeded the partical size of the contaminations, that is to say that the fact that one or more of the matrix/fibre materials is contaminated, does not have a detriment effect on the strength of the composite material. Furthermore, Polyplank $\mathrm{AB}$ has, in connection with the purchase of the machine equipment from F:a Greiner \& Söhne, obtained a patent relating to process technology for mixing plastic waste with different melting indexes.

\section{The waste problem became an opportunity}

The basic thesis has been that "a waste deposite is an unsorted raw materials store". This means that when correctly dealt with waste is a very large resource .

Along with increasing volumes and changes in the composition of waste, the waste management has developed into an increasingly greater problem, technically as well as economically and from an environmental aspects.

The "light" waste categories have from the recovery-responsible party's aspect, for a long time been paper,metal,glass,etc. Previously, the mixed plastics waste has, due to its heterogeneous nature, been, from the wastedepositing party's aspect, impossible to sort up and, from the recovery responsible party's aspectto recover. To this should be added that the waste is largely contaminated. In addition, deposited plastics waste has constituted a preventive factor in connection with trials to recover gas from waste deposits.

This project has turned the preconditions the other way and set out from the mixed plastics waste being a group of materials which, together with short organic fibres, are to constitute the final material composite Polyplank. 
The access to raw material for the Polyplank process is almost endless from a national as well as a global aspect.

\section{ACKNOWLEDGEMENT}

I will thank Stig Nilsson for a unforgetable time during the research and development within this project. We have not reached our goal, a financially viable buisness idea, the company Polyplank $\mathrm{AB}$, if we had not been a couple. 